$\mathbb{T}$ periodica polytechnica

\author{
Transportation Engineering \\ $37 / 1-2(2009) 65+69$ \\ doi: 10.3311/pp.tr.2009-1-2.11 \\ web: http://www.pp.bme.hu/tr \\ (c) Periodica Polytechnica 2009
}

RESEARCH ARTICLE

\section{Greenhouse gas emission of Hungarian transport sector}

\author{
Ádám Török
}

Received 2008-03-03

\begin{abstract}
Mobility is important for welfare. Therefore, the community must be able to provide its citizens and the commercial sector with a safe, efficient and reliable transport system. This system must be accessible to everyone under the same conditions, and must contribute towards countryward employment and growth. The transportation sector, led by the automobile, has been cited constantly as a major contributor through human intervention to climate change. In future, greenhouse gas emission and global warming will be key issues for society. Short of banning car use, the challenge remains one of understanding better what mix of actions might contribute in non-marginal ways to reducing the growth of greenhouse gas emissions and the absolute amount of carbon dioxid produced by automobiles. This paper evaluates instruments aimed at a number of policy objectives linked to efficiency, sustainability and equity, focusing on social surplus gains in addition to cost effectiveness; but in particular the ability to reduce carbon dioxid. Since one of the biggest challenges the community faces is to effectively reduce greenhouse gas emissions, this presupposes a transport-efficient society.
\end{abstract}

\section{Keywords}

carbon dioxid emission $\cdot$ climate change $\cdot$ mobility

\section{Ádám Török}

Department of Transport Economics, BME, H-1111 Budapest Bertalan L. u. 2., Hungary

e-mail: atorok@kgazd.bme.hu

\section{Introduction}

The European Conference of Ministers of Transport (2007) review of progress in Organisation for Economic Development (OECD) countries suggests that measures adopted to date in the transport sector should cut $\mathrm{CO}_{2}$ emissions by 2050, approximately $50 \%$ of the projected increase in emissions between 1990 and 2010 otherwise this would have serious conseqences for both the natural environment and human well-being, as you can see the tendecy on Fig. 1 .

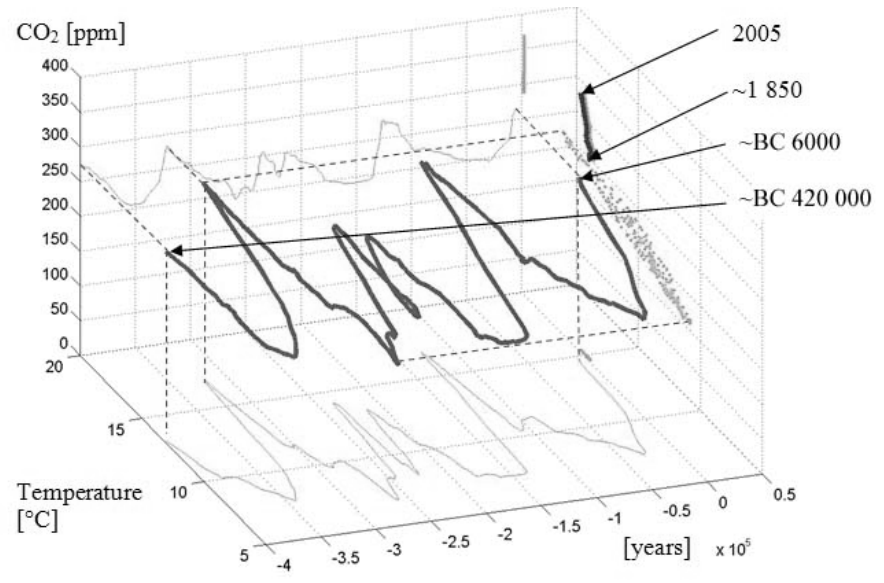

Fig. 1. Correlation of temperature, $\mathrm{CO}_{2}[1]$

Passenger car demand and use is one key sector of fossil fuel consumption and as such a contributor to anthropogenic GHG emissions and driver of climate change (Fig. 2). Road transportation operates on oil as the fuel of choice but first signs of a diversification of the fuel base have appeared, favoring natural gas, biofuels and synthetic fuels. Global transportation energy use accounts for roughly $25 \%$ of global carbon emissions from energy use (Fig. 3). Road transport is currently the dominant modal sector in contributing to $\mathrm{CO}_{2}$ emissions, with road passenger modes accounting for close to two-third of emissions. The Hungarian transport sector is responsible for significant share of the total national energy consumption, and therefor could significantly contribute to saving energy and greenhouse gas mittigation in Hungary. For evidence-based design of policies, it is important to understand the reason behind the dynamics of energy consumption and its structure in the Hungarian 
transport sector. The level of future emissions will depend in large part on the growth of populations and economies and on advances in technology.

\section{Global greenhouse gas emission}

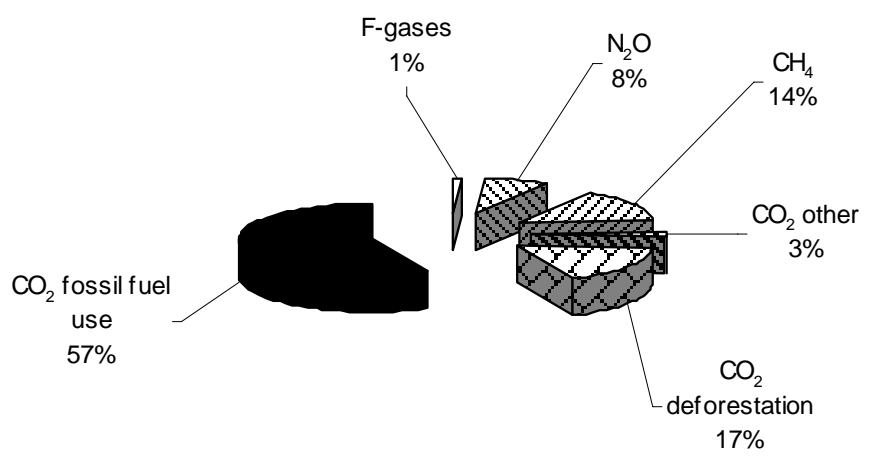

Fig. 2. Global greenhouse gas emission [2]

\section{$\mathrm{CO}_{2}$ emission caused by humanity}

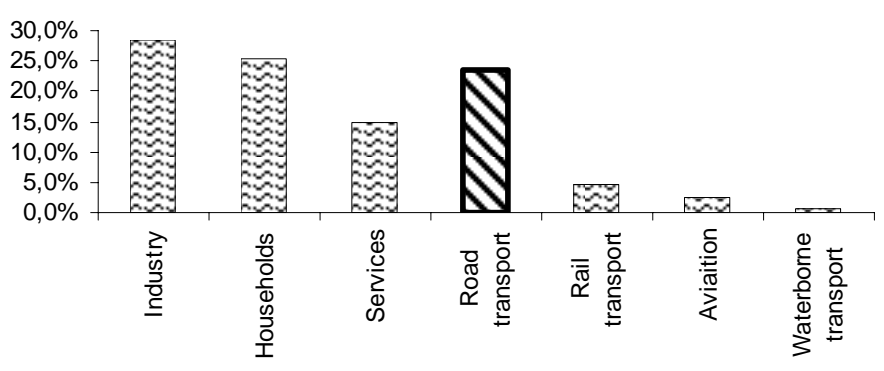

Fig. 3. Carbon dioxide emission of humanity [3]

There were decreasing emission of $\mathrm{CO}_{2}$ in major energy consuming sectors except for the transport. The share of emissions is projected to rise to about $25 \%$ if business-as-usual patterns of mobility are to prevail (OECD/IEA, 2004). I analysed the car related fuel consumption and estimated the associated $\mathrm{CO}_{2}$ emissions, which are calculated on the basis of chemical equation. The level and dynamics of transport related GHG emissions challenge international climate policies. Pursuing ambitious climate goals like the $+2^{\circ} \mathrm{C}$ target, to which the EU itself has committed, requires a long term reduction of more than $50 \%$ by 2050 compared with a 1990 baseline and a reduction of more than $90 \%$ until the end of the century (WBGU, 2007). The transport sector has to contribute to emissions abatement because other energy consuming sectors are unable to compensate for transport related emissions. The persisting problem of increasing emissions from transport is mirrored in multiple studies on decarbonizing and decoupling transport emissions from economic growth, e.g. IEA (1993, 2001), OECD (2006) and EEA (2007). However, national or supranational attempts to cut emissions from the transport sector have not been able to reverse the current trends in growing transport emissions.

With potential substitution of hydrogen for fossil fuels, the possibility that the road transport sector reduces its relative con- tribution to $\mathrm{CO}_{2}$ is real. Achieving major reductions in GHG emissions in the road passenger transport sector is not beyond the realms of possibility (European Conference of Ministers of Transport, 2007). Reducing GHG emissions however must be assessed in the context of cost effectiveness. There are a number of possible ways of reducing $\mathrm{CO}_{2}$ that deliver equivalent reductions; however some impose greater costs on society than others. Examples include variable user charges and a carbon tax, but the change in consumer surplus and end user money and time costs are likely to be substantially different, as are the revenue implications for government.

\section{Modelling $\mathrm{CO}_{2}$ emission}

Rather than ignoring the problem and following a businessas-usual approach, the international community could decide to make a concerted effort to lower its greenhouse gas emissions. While the inertia of the climate system now makes some warming inevitable, we can limit future climate change by stabilizing and then reducing emission. One aim is to calculate global $\mathrm{CO}_{2}$ emissions from passenger car use. Carbon dioxide is produced when fossil fuels are used, burnt.

The commercial intensity (i.e. fuel consumption) of the road transport sector has increased considerably during the past two decades. It is attributed generally to a larger share of traffic handled by road transport, especially by trucks hauling goods over longer distances, and rapid growth of energy-intensive private modes of road transport. Comparatively higher growth rates (and volume of use) have been observed in gasoline consumption beyond the mid-1990s. The expansion of cheaper diesel vehicles caused rapid growth in the demands for gasoline in recent years.

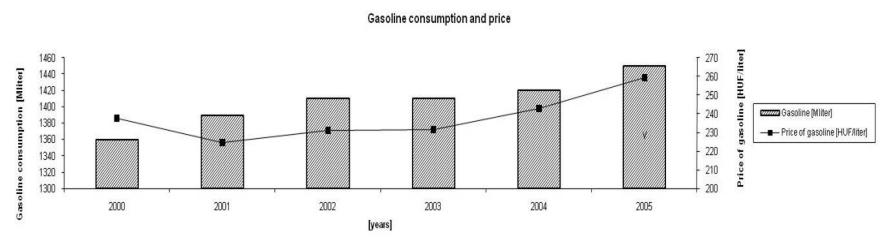

Fig. 4. Gasoline consumption and price in Hungary [4]

\subsection{Gasoline consumption, price and $\mathrm{CO}_{2}$ emission in Hun-} gary

The total, national gasoline consumption has increased from nearly 1360 million litres of gasoline in 2000 to almost 1450 million litres of gasoline in 2005 [4], registering 100 million litres of increasing. The gasoline consumption mentioned above has been consumed by motor vehicles in Hungary. According to my modelling that amount of gasoline in 2005 with perfect burning would have caused $1827000000 \mathrm{~m}^{3}$ of CO2 emission and used $2697000000 \mathrm{~m}^{3}$ of oxygen from our athmosphere (Atmosphere of Earth is: $1083319780000 \mathrm{~km}^{3}$ !) 


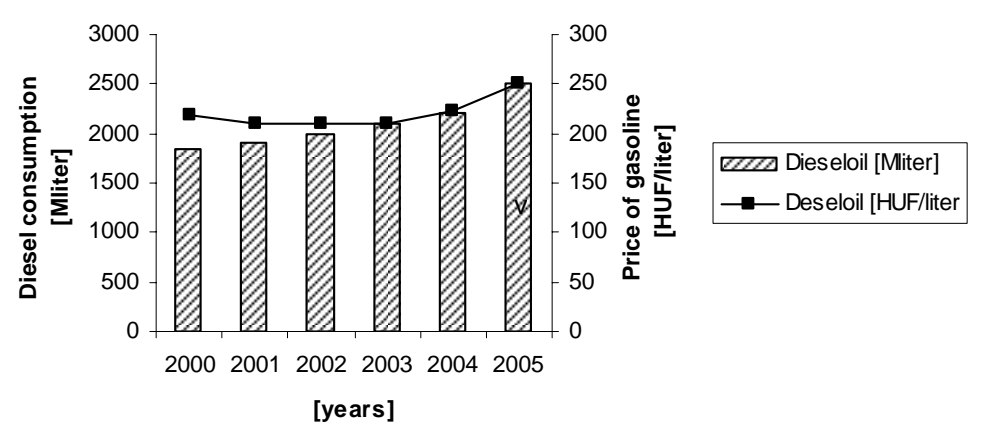

Fig. 5. Dieseloil consumption and price [4]

\subsection{Dieseloil consumption, price and $\mathrm{CO}_{2}$ emission in Hun- gary}

The total diesel consumption has increased from nearly 1800 million litres of diesel oil in 2000 to almost 2500 million litres of diesel oil in 2005 [4], registering 700 million litres of increasing. The diesel oil consumption mentioned above has been consumed by motor vehicles in Hungary. The relative share of diesel-powered vehicles has registered an increasig trend during the 2000-2005 period, diesel oil consumption has been observed to increase as well due to increase in freight and passenger traffic demands. All the freight and passenger transport vehicles (light, medium and heavy-duty commercial vehicles) have been powered mainly by diesel engines in Hungary. According to my modelling that amount of diesel oil in 2005 with perfect burning would have caused $3417500000 \mathrm{~m}^{3}$ of $\mathrm{CO}_{2}$ emission and used $5187500000 \mathrm{~m}^{3}$ of oxygen from our athmosphere (Atmosphere of Earth is: $1083319780000 \mathrm{~km}^{3}$ !)

\section{Reducing $\mathrm{CO}_{2}$ emission}

Because our socio-economic and decision-making system are also prone to inertia, even a target of $3^{\circ} \mathrm{C}$ would require us to start taking serious actions now. So delay is clearly no longer an option: the next two or three decades will be critical for avoiding the most serious consequences of global warming. Reducing greenhouse gas emission will cost money, but the amounts required are clearly affordable (Table ??). It is important to remember that climate policies can bring many win-win benefits.

Recently, sectoral approaches to emissions reduction have been gaining attention in international/national climate policy, i.e. in the design of a post-Kyoto agreement [6]. A sector wide approach to emissions mitigation may — in certain cases - be more successful than national approaches, as competitiveness risks and carbon leakage can be overcome. A sectoral approach is particularly interesting for internationally oriented sectors and their businesses, given a fairly limited number of actors, such as, for example, the car manufacturing industry. An essential step to sectoral abatement targets is to quantify global sectoral and regionalized baseline scenarios of $\mathrm{CO}_{2}$ emissions.

Importantly, the assessment of the overall impact of any policy instrument or mixes of instruments must be established through a framework that can account for the system-wide responses and not just the obvious direct and partial responses. Although there will be adjustments beyond the transport sector, there is great merit in tracking the ways in which specific policy instruments impact, in direct and indirect ways, on activities that are linked to transportation and location decisions for the population of interest. To understand how a system-wide approach can identify the impact of a specific policy instrument, consider a fuel tax increase. The imposition of an increase in the tax on automobile fuel, via its impact on unit operating cost has an immediate and direct influence on: the use of each vehicle for particular trips such as the commuter trip; i.e. mode choice, which includes both a switch to public transport and vehiclesubstitution from within the household's vehicle park, a possible change in the timing of the commuter journey to reduce the increased costs associated with traffic congestion, and hence a change in the overall and non-commuting use of each automobile available to a household. It also directly affects the household's choice of types of automobiles from the set of conventional and hybrid-fuel vehicles. The indirect impacts include a change in residential location over time via the change in modal and spatial accessibility to work opportunities and a change in the number of vehicles in a household (given the increased operating costs). Changes in residential location may further affect the use of each automobile, as well as the mix of urban commuting and non-commuting, and non-urban kilometers. The adjustment in commuter travel may also affect non-commuting car use if a vehicle previously used for commuting is released for use by another non-working member of the household. Some adjustment in the loss rate of automobiles will also occur

The demand for vehicles and transport fuel responds only weakly to higher prices. Prospects for reducing emissions therefore depend very much on advances in transport technologies and regulations encouraging their adoption. Improving road vehicles will require continued technological progress together with strong policies to ensure that engineers focus on boosting fuel economy rather than on increasing horsepower and vehicle mass [5]. Providing public transport systems and promoting walking and bicycling can further reduce emissions significantly. Making towns and cities more pedestrian friendly should 
be a top priority for urban planners. The associated health and other benefits can also be significant. Governments can play a major role in convincing industry and consumers to be climatefriendly by providing incentives that are clear, predictable, long term and robust. It is important toensure that policies are not counterproductive. Many public policies promoting the development, deployment and and diffusion of new technologies are applicable to a wide range of economic sectors. Examples of policies and measures already in use:

- Regulations and standards (fuel economy standards, emission standards)

- Taxes and charges for raising the costs of emission

- Subsidies or financial incentives that reward the buyers and sellers of low emission technologies, thus enabling these technologies gain a footing in the marketplace.

- Research and development programmes, which can lower the cost of launching new technologies

- By reflecting the true cost of emissions, it can be a signal to users to cut emissions. It can also stimulate the research and development of low carbon technologies.

This paper aimed to estimate the transport related carbon dioxid emission in Hungary by the fossil fuel consumption. This can be the basis of further research on true cost of transport related emission.

\section{Conclusions}

This paper evaluates potentially effective instruments that are aimed at a number of policy objectives linked to the triplebottom line - efficiency, sustainability and equity; but in particular the ability to reduce $\mathrm{CO}_{2}$. Reducing greenhouse gas emission will have to be one of the international community's top priorities over the coming decades. There wll be many difficulties and detour along the road to build climate friendly economies.

Fossil fuel will dominate our global energy supply for the next several decades unless we make deliberate changes. The commercialization of new types of bioenergy may also offer significant potential. Business-as-usual emissions scenarios of passenger car demand and use reveal a development of emissions portfolios that is far from achieving stabilization and thus far from striving toward climate protection, assuming other energy consuming sectors will not be able to compensate for transport related emissions growth. Projections validate a trend towards continued growth in fuel consumption and correlated $\mathrm{CO}_{2}$ emissions, which could be substantial if the behavioral and technological aspects of passenger vehicle use persist. But the analysis puts forward a remarkable potential for mitigation through technological improvements in fuel economy standards. One of the cheapest options for reducing emission is the fuel saving in vehicles.
One of the cornerstones of a transition towards more climate friendly on-road mobility schemes must therefore be to optimal for technological innovations in emissions reduction, in particular, through fuel economy improvements and moving transportation away from its persistent dependence on oil to a more sustainable track through alternative propulsion systems like hybrid technologies.

The road transport sector of Hungary has been estimated to emit $4242500000 \mathrm{~m}^{3}$ of $\mathrm{CO}_{2}$-equivalent emissions in 2000 that increased to $5244500000 \mathrm{~m}^{3}$ in 2005 . Therefore, it is important that accurate emission inventories are prepared for the road transport sector in order to design and implement suitable technological and policy options for appropriate mitigation measures. An attempt has been made in the present exercise to reduce uncertainties in the emission estimates of the road transport sector. It is evident from the discussion that improvement in documentation of activity data (i.e. fuel use) at segregated levels of consumption by sources and fuel types is necessary at the compilation stage itself along with the generation of country specific emission factors for estimating the GHG emissions. The uncertainties associated with the activity data and emission factors could then be reduced, at least at the national level, for major categories of gasoline and diesel-powered vehicles.

Reducing greenhouse gas emission will cost money, but the amounts required are clearly affordable. It is important to remember that climate policies can bring many win-win benefits. Reducing greenhouse gas emission will have to be one of the international community's top priorities over the coming decades. There will be many difficulties and detour along the road to build climate friendly economies.

An alternative or complementary policy approach can be the promotion of intermodal services, mainly in freight transport. Higher market share of intermodal transport can lead to lower performance volumes in unimodal road haulage. Intermodal transport, however, still needs to be supported by different public interventions as it is not competitive enough [7].

\section{References}

1 Török Á, Developing the implementation strategies on which the modernisation of road transport pricing schemes are based, Budapest, 2008.

2 Climate Change 2007: Mitigation of Climate Change.

3 Tánczos K, Török Á, The linkage of climate change and energy consumption of Hungary in the road transportation sector, Transport Journal (2007), no. 2, 134-138.

4 Lukács A, Pavics L, Macroeconomical opportunities of energy efficiency in transport sector, Budapest, 2006.

5 Horváth Á, Vári I, Zatykó J, Zöldy M, Car Industry developments - oil industry challenges, MOL Scientific Publications (2007), no. 2, 122-137.

6 Baron R, Sectoral approaches to greenhouse gas mitigation. Scenarios for integration, 2006. OECD/IEA, Paris, Presentation.

7 Bokor Z, Hungary: role of the state in intermodal transport logistics services, Logistics and Transport Focus 9 (2007), no. 8, 37-41. 
Tab. 1. Climate Changing startegies[1]

\begin{tabular}{|c|c|c|c|}
\hline & & \multicolumn{2}{|c|}{ Do we do anything against climate change? } \\
\hline & & Yes & No \\
\hline \multirow{5}{*}{ Is there climate changing? } & Yes & - Changing behaviour & $\begin{array}{l}\text { Increasing damages, both frequecy and } \\
\text { value }\end{array}$ \\
\hline & & - Changing society & \\
\hline & & - Changing economy & \\
\hline & & - Decreasing damages & \\
\hline & No & $\begin{array}{l}\text { - Changing behaviour } \\
\text { - Changing society } \\
\text { - Changing economy }\end{array}$ & $\begin{array}{l}\text { Stay in current form of behaviour, society } \\
\text { and economy }\end{array}$ \\
\hline
\end{tabular}

\section{Estimated pollution of transport sector in Hungary}

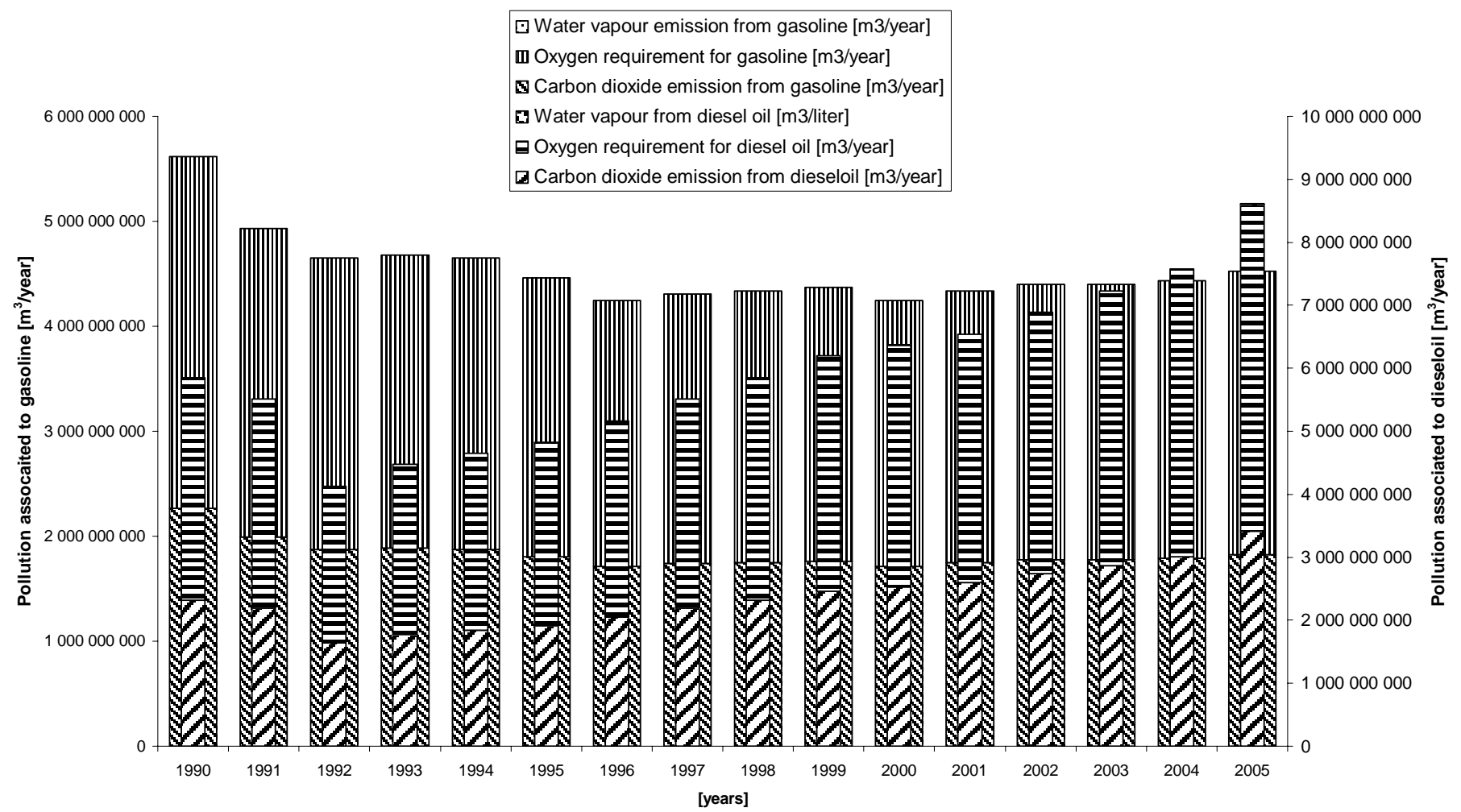

Fig. 6. Estimated emission of transport sector in Hungary [7] 